\title{
How to support quality of life of children with cancer and their parents?
}

\author{
Charlotte Grégoire $^{1 *}$, Marie-Elisabeth Faymonville ${ }^{2}$, Audrey Vanhaudenhuyse ${ }^{2}$, Christophe Chantrain ${ }^{3}$, Jennifer Marini ${ }^{3}$ and Isabelle \\ Bragard $^{1}$
}

${ }^{1}$ Public Health Department and GIGA Consciousness, University of Liege, Liege, Belgium

${ }^{2}$ Algology-Palliative Care Department, CHU Liege, and Sensation and Perception Research Group, GIGA Research, University of Liege, Liege, Belgium

${ }^{3}$ Paediatric Haematology/Oncology and Immunology Department, CHC Esperance, Liege, Belgium

\section{Introduction}

Procedure-related emotional distress, fatigue, and anxious and depressive symptoms are frequent in children with cancer [1-4]. Their parents also suffer from emotional distress [5]. It is known that child's and parents' emotional distress are linked [6], which underlines the importance to work with the whole family in paediatric psychooncology. Several psychosocial interventions had positive results on the well-being of children with cancer and their parents [7,8]. These therapeutic groups for children and for parents are generally led in parallel, to allow parents to help and support their child in the therapeutic process [9]. Some of these are also based on hypnosis and showed positive results on procedure-related pain and emotional distress $[9,10]$.

\section{Use of hypnosis in oncology}

Last years, studies assessed the efficacy of hypnosis to cope with several cancer-related symptoms in adults. Hypnosis can be divided in three main components: absorption (the ability to be totally involved in an imaginary experience); dissociation (the mental separation with the environment); and suggestibility (the ability to accept and follow the therapist's suggestions or instructions) [11]. Indeed, during the hypnotic procedure, a therapist suggests to a patient some changes in their sensations, perceptions, thoughts or behaviours, which allow the person to retrieve some control over their life and to use their personal resources to modify dysfunctional behaviours or situations [12]. In therapeutic groups, this technique is generally associated with other approaches, such as cognitive-behavioural therapy of self-care training, and in these cases, it is often proposed to adults with cancer, with positive effects on pain, emotional distress and fatigue [13-15]. Few studies concerned children with cancer and their parents.

\section{A need for multicentre study implementation}

Our team in Liège-Belgium developed, based on scientific literature, previous studies, and clinical practice, a group intervention combining hypnosis and self-care learning. First, it was proposed to adults with cancer, with positive results on quality of life $[12,14]$. Then, an adapted version of this combined intervention was proposed to children with cancer and their parents, given the difficulties faced by the whole family. Two groups were created and led in parallel: one for the children and one for their parents. The thematic and exercises were similar in both groups but were adapted to the age of the children. As the pilot study led to encouraging results in terms of adherence and participants' satisfaction [16], a quasi-experimental protocol has been implemented since 2018 in Liège, aiming at improving emotional distress, fatigue and adaptation of children with cancer and their parents. However, some difficulties have been encountered during this process. As paediatric cancers are fortunately rarer than in adults, this leads to small heterogeneous samples of participants in terms of age, types of illness and treatment, making difficult to obtain reliable data. Plus, their parents are not necessarily available for all the sessions as well, as they have a lot to deal with too. Thus, researchers have to develop multicentre studies and share their strengths, to have accurate results and improve hypnosis-based interventions in paediatric oncology. This must be encouraged by the benefits reported by our participants, saying that intervention combining self-care and hypnosis allowed to 'feel more relaxed,' 'be more assertive', 'help (their) children to be calmer' and 'should be proposed to more children with cancer and their parents'

\section{References}

1. Olson K (2014) Sleep-related disturbances among adolescents with cancer: A systematic review. Sleep Med 15: 496501. [Crossref]

2. Stuber ML (2012) Psychiatric Impact of Childhood Cancer. In: SKreitler, MWBenArush, \& Andrésrtin (Eds.), Pediatric Psycho-Oncology 43-51.

3. Trentacosta CJ, Harper FWK, Albrecht TL, Taub JW, Phipps S, et al. (2016) Pediatric cancer patients' treatment-related distress and longer-term anxiety: An individual differences perspective. J Dev Behav Pediatr 37: 753-761. [Crossref]

4. Tackett AP, Cushing CC, Suorsa KI, Mullins AJ, Gamwell KL, et al. (2016) Illnes Uncertainty, Global Psychological Distress, and Posttraumatic Stress in Pediatric Cancer: A Preliminary Examination Using a Path Analysis Approach. J Pediatr Psychol 41: 309-318. [Crossref]

5. Landolt MA, Ystrom E, Sennhauser FH, Gnehm HE, Vollrath ME (2012) The mutual prospective influence of child and parental post-traumatic stress symptoms in pediatric patients. J Child Psychol Psychiatry 53: 767-774. [Crossref]

6. Muglia-Wechsler A, Bragado-Álvarez C, Hernández-Lloreda MJ (2014) Effectiveness of psychological interventions intended to promote adjustment of children with cancer and their parents: An overview. Anales de Psicología 30: 94-104.

7. Mullins LL, Tackett AP, Suorsa KI (2016) Psychotherapeutic Modalities for Children with Cancer and Their Families. In: Abrams AN, Muriel AC, Wiener L (Eds.) Pediatric Psychosocial Oncology: Textbook for Multidisciplinary Care pp: 81-105.

8. Plante WA, Lobato D, Engel R (2001) Review of group interventions for pediatric chronic conditions. J Pediatr Psychol 26: 435-453. [Crossref]

${ }^{\star}$ Correspondence to: Charlotte Gregoire, Public Health Department and GIGA Consciousness, University of Liege, Liege, Belgium, E-mail: ch.gregoire@ uliege.be

Received: July 05, 2019; Accepted: July 22, 2019; Published: July 26, 2019 
9. Gold JI, Kant AJ, Belmont KA, Butler LD (2007) Practitioner Review: Clinical applications of pediatric hypnosis. $J$ Child Psychol Psychiatry 48: 744-754. [Crossref]

10. Kuttner L (2012) Pediatric hypnosis: Pre-, peri-, and post-anesthesia. Pediatr Anesth 22: 573-577. [Crossref]

11. Vanhaudenhuyse A, Jerusalem G, Charland-Verville V, Faymonville ME (2017) Intérêt de l'hypnose en oncologie et dans la pratique de l'hépato-gastro-entérologue. Hegel 7: 101-102.

12. Charland-Verville V, Faymonville M-E, Vanhaudenhuyse A, Raaf M, Grégoire C, et al. (2017) Apprentissage de l'autohypnose/autobienveillance en oncologiePour qui ? Comment? Dans quel intérêt? Une revue de la littérature internationale. Psycho Oncologie 11: 51-55.
13. Cramer H, Lauche R, Paul A, Langhorst J, Kümmel S, Dobos GJ (2015) Hypnosis in breast cancer care: A systematic review of randomized controlled trials. Integr Cancer Ther 14: 5-15. [Crossref]

14. Grégoire C, Bragard I, Jerusalem G, Etienne AM, Coucke P, et al. (2017) Group interventions to reduce emotional distress and fatigue in breast cancer patients: A 9-month follow-up pragmatic trial. Br J Cancer 117: 1442-1449. [Crossref]

15. Montgomery GH, Schnur JB, Kravits K (2013) Hypnosis for cancer care: Over 200 years young. CA Cancer J Clin 63: 31-44. [Crossref]

16. Grégoire C, Chantrain C, Faymonville ME, Marini J, Bragard I (2019) A hypnosisbased group intervention to improve quality of life in children with cancer and their parents. Int J Clin Exp Hypn 67: 117-135. [Crossref]

Copyright: $\odot 2019$ Grégoire C. This is an open-access article distributed under the terms of the Creative Commons Attribution License, which permits unrestricted use, distribution, and reproduction in any medium, provided the original author and source are credited. 